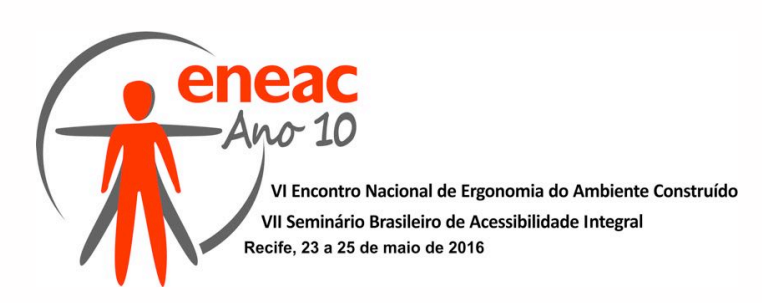

\title{
Maquetes Táteis produzidas a partir de Técnicas de Fabricação Digital: investigação de simbologia para orientação espacial de deficientes visuais
}

\author{
CENCI, Carlos Alberto (1); \\ BERNARDI, Núbia (2) \\ (1) Universidade Estadual de Campinas - UNICAMP, Arquiteto \\ e-mail:carloscenci@icloud.com.br \\ (2) Universidade Estadual de Campinas - UNICAMP, Professora Dra. da Faculdade de \\ Engenharia Civil arquitetura e urbanismo - FEC \\ e-mail:nubiab@fec.unicamp.br
}

\begin{abstract}
RESUMO
Este trabalho investigou simbologias de mapas/maquetes táteis para orientação espacial de pessoas com deficiência visual, afim de construir um repertório de linguagem gráfica que serviu de base para elaboração de duas maquetes táteis. Para a confecção dos objetos foram utilizadas ferramentas de fabricação digital. Na sequência foram realizados testes de usabilidade com usuários com deficiência visual.
\end{abstract}

Palavras chave: Orientação Espacial, maquete tátil, fabricação digital

\begin{abstract}
This research goal was the investigation of tactile maps/models for the spatial orientation of visual impaired people, in order to conceive a repertoire of graphic language which supported the elaboration of two tactile models.
\end{abstract}

Keywords: spatial orientation, tactile model, digital fabrication

\section{INTRODUÇÃO}

"Após escrever o texto original, soube que na verdade nossa pele é capaz de distinguir diversas cores; nós realmente vemos com nossa pele"(PALLASMAA, 2011).

Apesar de não possuir o sentido da visão, o cego pode usar outros sentidos para conhecer formas, ambientes e espaços através de um processo multissensorial. Segundo Ballastero (2003), para que seja possível a obtenção de tais informações deve-se "Adaptar a informação visual ao sentido de percepção sensorial mais adequado; dessa maneira uma imagem visual pode-se converter em tátil ou sonora" (BALLASTERO, 2003, p.13). O autor cita em outro trecho de seu livro, que "através das atividades de seu próprio corpo juntamente com o auxilio da informação verbal, e assim vai desenvolvendo uma percepção multissensorial. " 


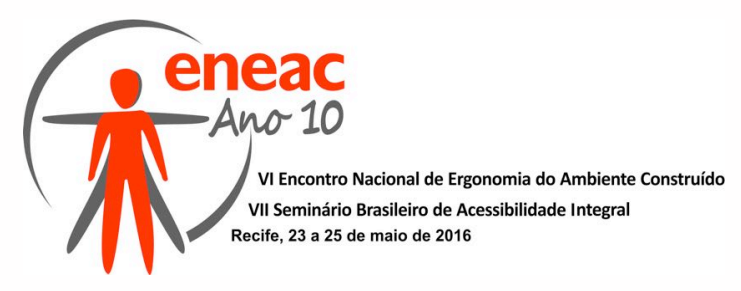

Cada elemento visual que compõe a imagem, tem em si um significado, e eles permeiam todos os lugares sendo a todo momento captados pelo cérebro. Mas quando falamos em observar cidade, e toda sua complexidade, sabe-se que é preciso saber olhar: "...o exercício de olhar além de atuar, solitariamente, também pode convocar um ou mais dos outros sentidos para em coalescência, viver a experiência visual." (OLIVEIRA, 2005, p.109). Deste modo através da multissensorialidade, o olho tão necessário para contemplar uma obra de arte transcende para outros sentidos aproximando o cego das imagens. Enquanto uma pessoa com visão cria seu sistema de símbolos visuais para definir seu conceito de cidade, a pessoa sem visão percebe a mesma cidade criada a partir de um conceito formado por todo um repertório de percepção sensorial além da visão. Parece ser uma habilidade extraordinária a de aprender símbolos e formar repertório de signos daquilo que não se percebe e se compreende com os olhos, porém muitas vezes essa habilidade só é desenvolvida com apoio suplementar e acesso a informação.

"A locomoção de pessoas com deficiência através do espaço urbano, bem como seu acesso aos locais de seu interesse, depende diretamente de estratégias de localização e orientação, as quais devem ser adaptadas e configuradas conforme as limitações dessa população. Indivíduos com deficiência visual necessitam de uma correta orientação espacial que lhes assegure um percurso autônomo e confiante. A descrição de um ambiente através de mapas táteis é um importante instrumento de orientação espacial e conseqüentemente um importante elemento da aplicação do Desenho Universal." (BELTRAMIN,2009).

Quando observamos a paisagem urbana ao nosso redor é necessário que a cidade se mostre com toda sua simbologia visual, para que possamos ler o que está a nossa frente, e para isso usamos o sentido da visão. Mas qual o mecanismo de compreensão e leitura do espaço que uma pessoa como deficiência visual tem para ler toda a complexidade das cidades? Pois afinal, sem ver, como se locomover, como compreender e expressar o entorno que o envolve e, principalmente, como se orientar num espaço construído para pessoas que enxergam? É fato que a cidade é um sistema complexo de comunicação, e a habilidade de ver é naturalmente o primeiro sentido a ser acionado neste ambiente.

\section{CONCEITUAÇÃO}

Foi realizado um processo de fundamentação teórica de tópicos relacionado à temas como Orientação Espacial, Wayfinding e leitura sobre instrumentos de Orientação Espacial voltados ao espaço arquitetônico, assim como um levantamento sobre métodos e técnicas de Fabricação Digital como suporte à acessibilidade.

Foram tomadas ações sistematizadas em etapas para chegar as maquetes táteis. A fabricação digital foi adaptada para se adequar as máquinas disponíveis no LAPAC $^{1}$, pois esse é um fator que define parcialmente a materialização do objeto final. Esta sistematização foi aplicada no desenvolvimento dos experimentos viabilizando verificar aspectos positivos e negativos desta abordagem.

\subsection{Fabricação Digital}

Fabricação Digital (FD), ou prototipagem rápida, pode ser entendido como a técnica de fabricar produtos através da conexão entre modelagem digital e máquinas. Para Lefteri (2008) existem 3 tipos básicos de máquinas de fabricação digital: Impressoras 3D, Máquinas de Corte (Laser, Faca ou jato d'água) e Máquinas de Usinagem. Se comparado a

\footnotetext{
${ }^{1}$ Laboratório de Automação e Prototipagem para Arquitetura e Construção. O LAPAC pertence a faculdade de engenharia civil, arquitetura e urbanismo da UNICAMP.
} 


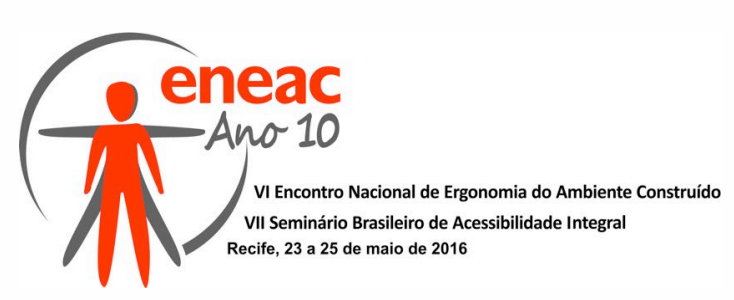

métodos tradicionais de produção, a FD apresenta vantagens de tempo e precisão, podendo gerar numerosas cópias de um mesmo modelo. Um dos pioneiros centros de pesquisa que se especializou nesse tema foi o MIT, Massachusetts Institute of Technology, desenvolvendo a ideia de implantar pelo mundo todo laboratórios de fabricação digital chamados FAB LAB. Lefteri (2008) observa que, em um futuro próximo, usuários domésticos serão capazes de fabricar uma grande variedade de artefatos utilizando meios digitais. Segundo Pupo:

\begin{abstract}
"A fabricação digital (Digital Fabrication) refere-se às tecnologias de controle numérico (CNC) sugerindo a transferência de dados de um programa de modelagem 3D para uma máquina CNC. Isso permite a produção de modelos em escala real de componentes construtivos diretamente de modelos digitais 3D... a fabricação digital permite resultados variáveis e não repetitivos. Induz ao conceito de mass-customization (customização em massa) permitindo o desenvolvimento de sistemas construtivos não padronizados através de diferenciações seriais e variações digitalmente controladas. Suas aplicações na arquitetura e construção são as mais variadas, desde a produção de fôrmas para concreto armado com formas especiais até a produção de ornamentos esculpidos em pedra que podem ser utilizados como "próteses" arquitetônicas em obras de restauro."(PUPO, 2008)
\end{abstract}

\title{
$2.2 \quad$ Mobilidade
}

Movimento é um ato intrínseco da espécie humana. Através do ato cognitivo de andar, o homem e toda idiossincrasia de seu corpo, se desloca e registra no repertório de sua espacialidade o mundo em sua volta. Andar a pé pode "transformar simbólica e fisicamente tanto o espaço natural como o antrópico." (CARERI, 2013). Assim surge a mobilidade, que nomeia a relação do movimento humano no espaço e no tempo. A relação entre caminhar e a cidade é brilhantemente estabelecida no livro "Walkscapes, o caminhar como prática estética", onde Fracesco Careri trata o ato de caminhar como um "ato primário na transformação simbólica do território... um instrumento estético de conhecimento e uma transformação física do espaço, convertido em intervenção urbana".

Caminhar é o principal meio de locomoção do público alvo deste trabalho; Para que um indivíduo seja considerado completamente incluído, sem discriminação, em nossa sociedade, é exigido que ele consiga se locomover de forma independente.

\subsection{Wayfinding}

Wayfinding pode ser explicado como uma disciplina do design gráfico que codifica elementos visuais afim de que usuários cheguem a um destino, situem-se no espaço, englobando processos perceptuais, cognitivos e comportamentais envolvidos no alcance do destino. (ARTHUR, PASSINI, 2002).

Um projeto que utiliza Wayfinding baseia-se em estudos e pesquisa sobre cognição e psicologia para conceber espaços e produtos construídos que facilitam a circulação de pessoas através de ambientes urbanos e edifícios. Permite as pessoas a (1) determinar a sua localização dentro de um ambiente; (2) determinar o seu destino; (3) desenvolver um plano para levá-los a partir de sua localização para o seu destino; e (4) executar o planta e negociar as alterações necessárias (HUNTER, Susan. 2010).

O termo Wayfinding surgiu na segundo metade do século $X X$, utilizado pelo arquiteto Kevin Lynch em seu livro o "A imagem da Cidade (1960., se referindo a um conjunto de elementos urbanísticos que permitem ao indivíduo navegar na cidade (caminhos, limites, marcos urbanos, entroncamentos, vizinhança.).

A primeira barreira que um deficiente visual encontra nesse contexto é a orientação espacial. Pois afinal, sem ver, como se locomover, como compreender e expressar o 


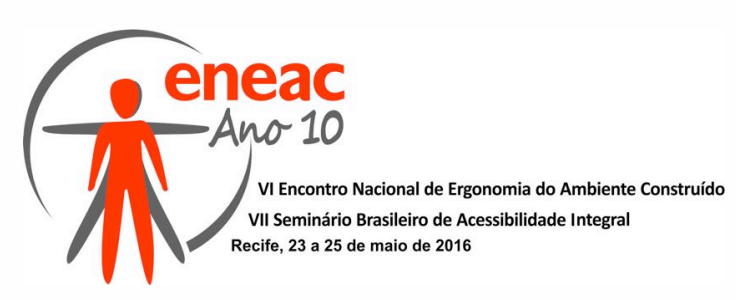

entorno que o envolve e, principalmente, como se orientar num espaço construído para pessoas que enxergam? Orientação espacial é a capacidade que o indivíduo tem de situarse e orientar-se, em relação aos objetos, às pessoas e ao seu próprio corpo em um determinado espaço. É saber localizar o que está à direita ou à esquerda; à frente ou atrás; acima ou abaixo de si, ou ainda, um objeto em relação a outro. É ter noção de longe, perto, alto, baixo, longo, curto (JOSÉ; COELHO, 1996, p.91-96).

Lynch dedica um capítulo inteiro de seu livro sobre a Imagem do Ambiente, sempre construída sob análise visual. Mas como se dá essa construção da "imagem", quando não existe o fator "visão"? Na primeira parte deste capítulo o autor nos conta que cada cidadão associa suas impressões sobre cada elemento da cidade à seu modo, construindo assim sua própria imagem da cidade. Toda percepção espacial de uma pessoa com deficiência visual é baseada em seu repertório construídos por percepções sensoriais além dos olhos. A cidade não é um corpo estável, ela está sempre se modificando. Como se orientar em um lugar onde objetos fixos são modificados, onde estabelecer o lastro?

\title{
2.4 Desenho Universal
}

Desenho Universal (DU), surge com o objetivo de definir projetos de produtos e ambientes para ser usado por todos, na sua máxima extensão possível, sem necessidade de adaptação ou projeto especializado para pessoas com deficiência. Este conceito se desenvolveu entre os profissionais da área de arquitetura na Universidade da Carolina do Norte - EUA.

\begin{abstract}
"...compreendendo a realidade de pessoas com deficiência, o profissional de design tem a oportunidade de visualizar as necessidades dos mais diversos tipos de usuários e assim tem um grande desafio pela frente ao projetar de acordo com os condicionantes legais, compreensão do espaço ao seu redor e de seu público enquanto desenvolvem um projeto expográfico". (BERGER,2009)
\end{abstract}

O Desenho Universal não é uma tecnologia direcionada apenas aos que dele necessitam; é desenhado para todas as pessoas. A ideia do Desenho Universal é, justamente, evitar a necessidade de ambientes e produtos especiais para pessoas com deficiências, assegurando que todos possam utilizar com segurança e autonomia os diversos espaços construídos e objetos.

O conhecimento das necessidades humanas para desenvolver projetos de arquitetura, urbanismo ou paisagismo não é apenas uma preocupação atual, pois até mesmo Vitruvius, em seus dez livros sobre a arquitetura, definiu a arquitetura em função de três princípios: venustas, fimirtas e utilitas (beleza, solidez e funcionalidade, respectivamente), correspondendo esta última à adequação do projeto às necessidades humanas (POLLIO, 2007).

\subsection{Deficiência Visual}

A visão também habita a cegueira. O que vê a cegueira? ? A minha cegueira é uma forma de visão. Com a cegueira, vê-se com o corpo inteiro".(BELARMINO,2000).

Segundo o dicionário Aurélio, Visão é o ato ou efeito de ver. A cegueira, por sua vez, é a ausência de visão. Adota-se deficiente visual como deficiência caracterizada pela anulação ou pelo sério comprometimento da captação das informações ambientais pelo canal perceptivo da visão, categorizando as pessoas respectivamente em cegas ou indivíduos com baixa visão (POYARES.; GOLDFELD, 2008 p. 40). 


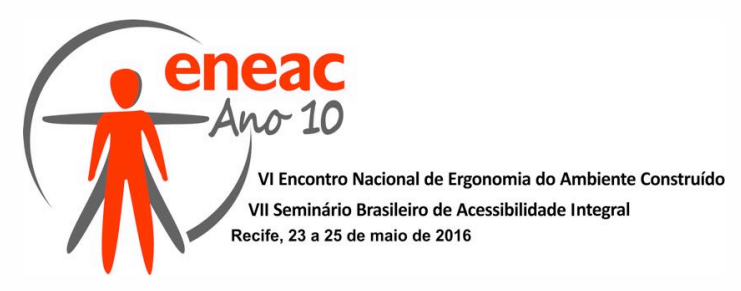

Para a pesquisadora Amiralian há diferenças notáveis de percepção de mundo, e repertório de linguagem entre os cegos que perderam a visão antes e depois dos 5 anos. No primeiro caso, o tipo de cegueira é chamado de congênita; Para o segundo, dá-se o nome de cegueira adquirida. A autora descreve que para criação menores 5 anos, portadoras dessa condição visual, não apresentam em seu diagnóstico qualquer resquício de registro de imagem (AMIRALIAN, 1997).

Cada elemento visual que compõe a imagem, tem em si um significado, e eles permeiam todos os lugares sendo a todo momento captados pelo cérebro. Mas quando falamos em observar cidade, e toda sua complexidade, sabe-se que é preciso saber olhar: "...o exercício de olhar além de atuar, solitariamente, também pode convocar um ou mais dos outros sentidos para em coalescência, viver a experiência visual" (OLIVEIRA, 2005, p.109). Deste modo através da multissensorialidade, o olho tão necessário para contemplar uma obra de arte transcende para outros sentidos aproximando o cego das imagens.

Enquanto uma pessoa com visão cria seu sistema de símbolos visuais para definir seu conceito de cidade, a pessoa sem visão percebe a mesma cidade criada a partir de um conceito formado por todo um repertório de percepção sensorial além da visão. Parece ser uma habilidade extraordinária a de aprender símbolos e formar repertório de signos daquilo que não se percebe e se compreende com os olhos, porém muitas vezes essa habilidade só é desenvolvida com apoio suplementar e acesso a informação.

\section{MATERIAIS E MÉTODOS}

Um método usual de comunicação espacial destinado a deficientes visuais é o alfabeto Braille, mas sabe-se que é possível a introdução de propostas de adaptação tátil e auditiva de conteúdos visuais para este público de acordo com a aplicação a que se destinam. Outras ferramentas, em conjunto com o Braille, podem compor um instrumento de leitura do espaço físico, como as maquetes e mapas táteis, aumentando as possibilidades de compreensão das informações espaciais (CAPELI, BERNARDI, 2011). Estas maquetes serão objeto de estudo deste trabalho.

Uma maquete tátil voltada para pessoas com deficiência visual não pode ser uma simples transcrição de uma planta arquitetônica comum, ela deve estar em função das necessidades específicas do usuário, não é uma simples questão de traduzir mapa em textura. Mãos não substituem os olhos; traduzir os conceitos naturalmente visuais para uma linguagem não visual devem conter estratégias específicas de entendimento do espaço.

Ruth Emília Nogueira (2010) realizou um experimento com mapas táteis na Universidade Federal de Santa Catarina, obtendo resultados muitos satisfatórios, como descrito em seu artigo "Elaboração de Mapas Táteis em Escala Grande: o caso do mapa do campus da UFSC". Destaca-se no trabalho desta pesquisadora o método de representação e comunicação adotado, que consiste em transcrever o desenho espacial arquitetônico utilizando formas de desenhos básicas como Ponto, Linha e Área, conhecido como linguagem PLA. Para o primeiro devem ser consideradas dimensões que não ultrapassem a ponta do dedo. Para o segundo, as linhas devem ter no mínimo $1,3 \mathrm{~cm}$ de comprimento para facilitar o entendimento. O último, se revela em um polígono fechado.

No método de Nogueira, elementos chave são extraídos de plantas, de desenhos, do espaço construído e em seguida transformadas em linguagem PLA, com grande atenção e cuidado para evitar o acúmulo de informações.

\subsection{Descrição da Metodologia Adotada}




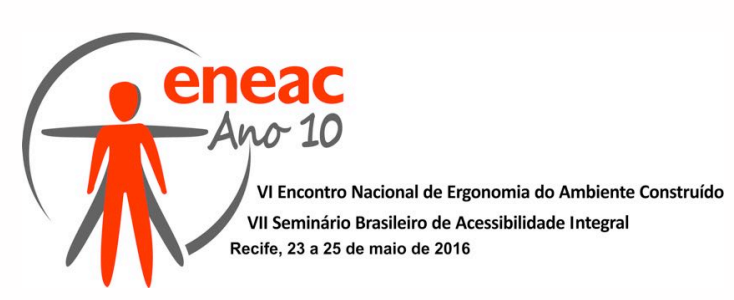

Baseado nas estratégias utilizadas no texto de Nogueira, foram desenvolvidos modelos de representação gráfica para a conversão da linguagem arquitetônica convencional para linguagem tátil. $O$ método de representação e comunicação adotado, consiste em transcrever o desenho espacial arquitetônico utilizando formas de desenhos básicas PLA.

Para explicar a metodologia, será utilizado como base a planta e o mapa urbano contidos na Figura 1 - Essas imagens são de espaços físicos genéricos tomados apenas para ilustrar a descrição do método.

Os desenhos tomados por base são então, transcritos em 3 tipos de linguagem tátil, afim de investigar e avaliar a compreensão de maquetes táteis com linguagens diversas e verificar a compreensão do fluxograma em relação ao espaço físico.

Temos então, segundo a metodologia descrita, o seguinte resultado:

Figura 1. Imagens de referência para explicação da Metodologia
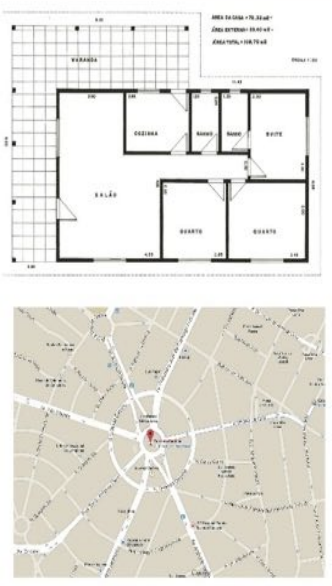

Fonte: o autor, 2015.
Figura 2 - Esquema de Linguagem adotado

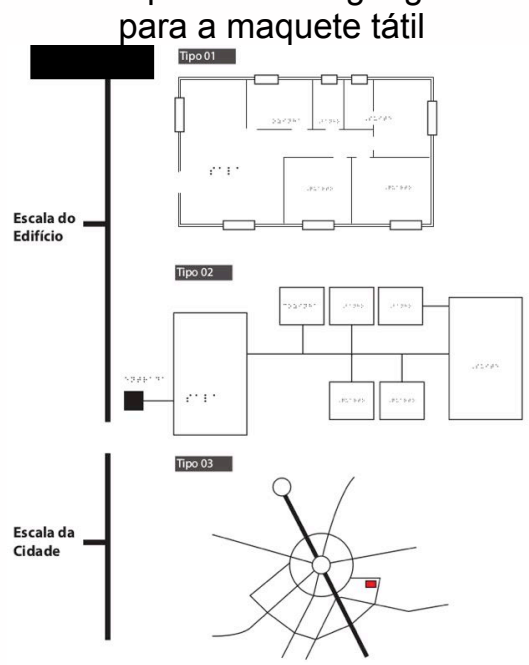

Fonte: o autor, 2015.

- TIPO 01: Planta baixa da Figura 1 transcrita para ser uma maquete tátil dos ambientes, que se aproxima da linguagem arquitetônica convencional. Neste tipo os espaços entre as linhas definem o ambiente, sendo o elemento de leitura mais importante. Essa tipo considera o tamanho em escala dos ambientes ( Figura 2).

- TIPO 02: Planta baixa da Figura 1, transcrita para ser uma uma "maquete-infográfica" com percursos e espaços representados por meio de fluxograma. Neste tipo as linhas são expressas como "caminhos" ou "corredores" e os ambientes são definidos por quadrados do mesmo tamanho, ou retângulos, porém de maneira apenas representativa. A Escala aqui não é importante ( Figura 2)

- TIPO 03: Mapa urbano da Figura 1, transcrita da mesma forma do tipo 02, porém direcionado para a escala da cidade ( Figura 2) .

$\mathrm{Na}$ sequencia metodológica, inicia-se um processo de vetorização e digitalização dos "Tipos", e deve-se produzir uma maquete tátil física para cada linguagem, utilizando ferramentas de fabricação digital. Quando as maquetes estiverem produzidas, elas serão testadas e avaliadas a partir de entrevista e atividades de percurso com usuários. 


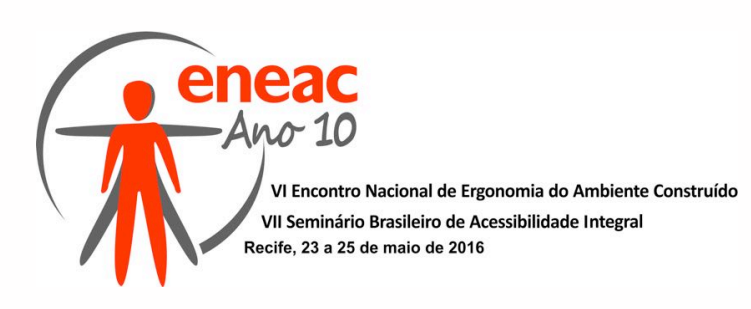

\section{EXPERIMENTOS}

Com a finalidade de aplicar o método descrito, foram construídas duas maquetes táteis, baseadas no espaço físico real de um instituto especializado no público alvo desse trabalho. O local escolhido foi o Instituto Campineiros de Cegos Trabalhadores (ICCT), fundado em 1933, sendo referência regional no suporte a requalificação de pessoas com DV oferecendo apoio psicológico, terapêutico, esportivo e educacional aos usuários.

Para este local foi fabricada uma "maquete-infográfica" (Tipo 02) com percursos e espaços representados por meio de fluxograma, e uma maquete tátil dos ambientes (Tipo 01), que se aproxima da linguagem arquitetônica convencional. As maquetes táteis foram produzidas com o apoio de uma cortadora a laser do LAPAC.

Havia no escopo inicial do trabalho, a intenção de realizar dois experimentos diferentes para avaliar os sistemas de linguagem tátil, exemplificados na Figura 3. No entanto, por conta das dificuldades burocráticas envolvida nos testes e pelo tempo curto da Iniciação Científica (apenas 6 meses), as atividades foram reduzidas para se concentrar apenas no experimento 01

Figura 3 - Descrição dos experimentos

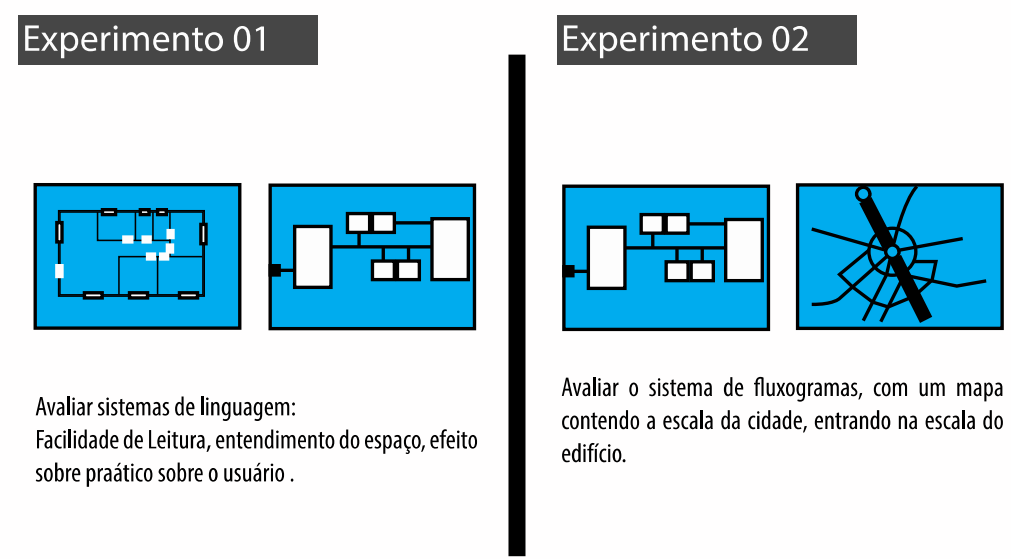

Fonte: o autor, 2015.

\subsection{Experimento 01}

\subsubsection{Processo de Desenho em CAD}

Primeiramente, depois de negociação com a diretoria do ICCT, foram levantados os documentos de representação gráfica existentes nos arquivos do Instituto. E foram encontradas duas plantas do edifício principal de épocas diferentes, correspondentes a Figura 4. 

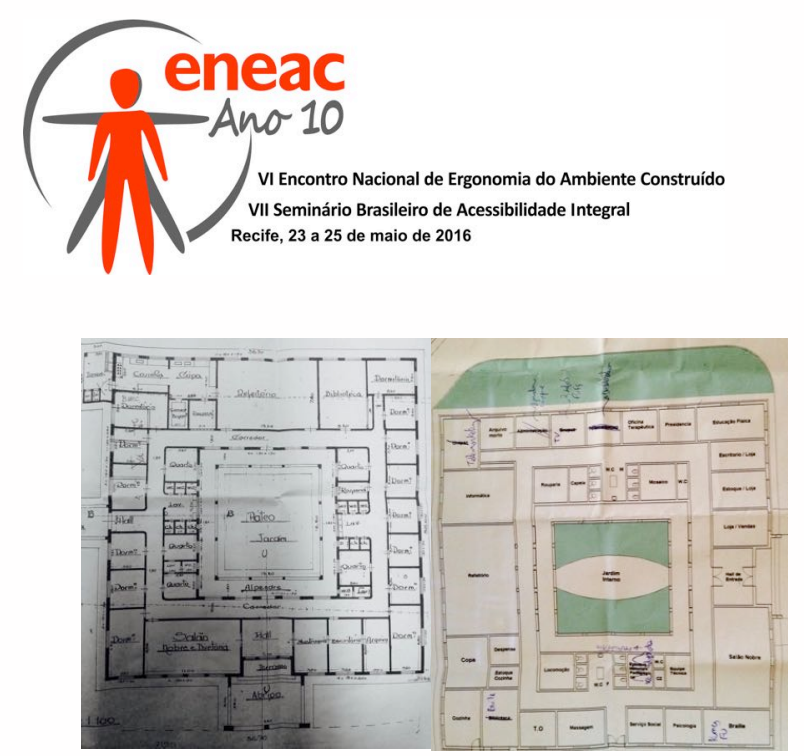

Fonte: o autor, 2015

Foi detectada uma desatualização entre os ambientes apresentados nas plantas e o uso real do espaço. Para produzir um produto mais fiel a disposição atual das atividades do ICCT, foi realizado um levantamento fotográfico e em forma de desenhos para conferir se a disposição dos ambientes ainda eram as descritas nas plantas, afim de produzir um desenho vetorial atualizado do espaço. Em seguida houve um processo de transcrição da linguagem visual das plantas fotografadas, para a linguagem dos desenhos do tipo 01 e 02 (Figura 2) - para essa tarefa foi utilizado o software AutoCAD, de uso muito comum entre arquitetos e engenheiros para elaboração de desenhos técnicos $2 \mathrm{D}$, com inúmeras possibilidades de criar desenhos vetoriais.

\subsubsection{Fabricação das Maquetes}

Seguindo com o experimento, entrou-se numa fase de escolha do material e da máquina a ser utilizada. Mãos não enxergam da mesma forma que os olhos, portanto o material de ser escolhido deve ser eficiente para o toque e fricção com as mãos, sendo uma observação que de ser priorizada em relação a aparência do material. Viabilidade de produção, durabilidade e textura foram características consideradas na produção. Foi escolhido então a fórmica para representação dos delimitadores de espaço e dos caminhos; e o MDF para a base da maquete. O uso de materiais muito ásperos deve ser evitado, além de ser necessário ter atenção aos materiais que aparentam ter boa textura, mas que podem ser tóxicos ou machucar o usuário (ALMEIDA e LOCH, 2005). Após digitalização dos desenhos, inicia-se a próxima etapa do processo de fabricação. As Figuras 5 e 6 mostram o resultado final da fabricação.

Figura 5 - Maquete Tipo 01, comparada a planta real.

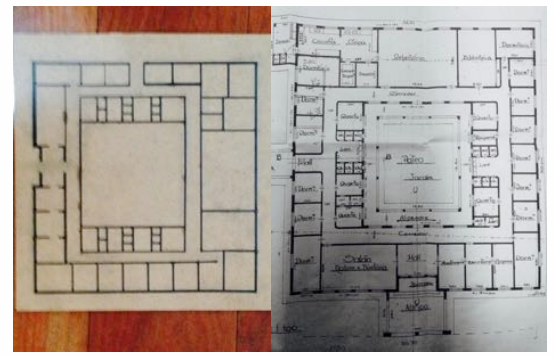

Fonte: o autor, 2015.
Figura 6 - Teste de papelão, e sequencia de produção da maquete Tipo 02.

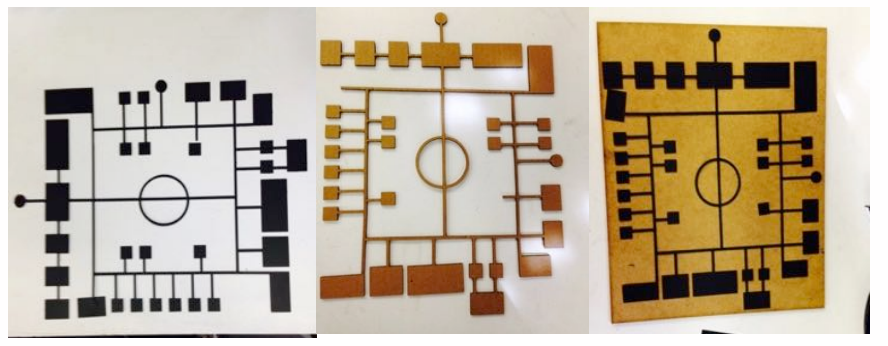

Fonte: o autor, 2015.

\subsubsection{Entrevista}




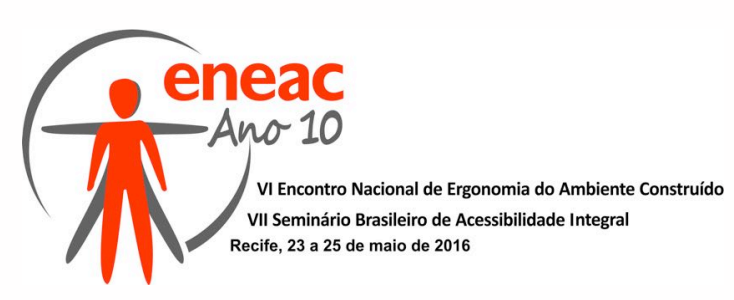

Após a fabricação, a pesquisa entrou em um processo de prospecção de institutos, relacionados ao tema, e o local escolhido para pesquisa foi o ICCT, descrito anteriormente. Houve a necessidade de um pedido de autorização formal para entrada, registro fotográfico e acesso ao acervo de plantas do instituto; assim como para a solicitação de voluntários para avaliação da maquete.

O pedido foi aceito e houve um convite, direcionado ao aluno autor desta pesquisa, para participar durante três dias das aulas e atividades. Durante o tempo de permanência no ICCT, foram disponibilizados 5 voluntários aleatórios, com diferentes perfis de cegueira, idade e escolaridade.

A atividade realizada com os voluntários consistiu em uma entrevista para aplicação do questionário, e com uma atividade de percurso baseado na leitura tátil da maquete. Segue a ordem de como a dinâmica aconteceu: (1) Perguntas preliminares; (2) Leitura da Maquete 02 (Figura 10); (3) Perguntas Após Leitura Tátil da Maquete 02; (4) Percurso (Figura 11) ; (5) Perguntas Após Percurso da Maquete 02; (6) Leitura da Maquete 01 (Figura 12); (7)Percurso; (8) Perguntas Após Percurso da Maquete 01; (9)Percurso; (10) Perguntas após o experimento com as duas maquetes;

Figura 7. Leitura da Maquete 02 .

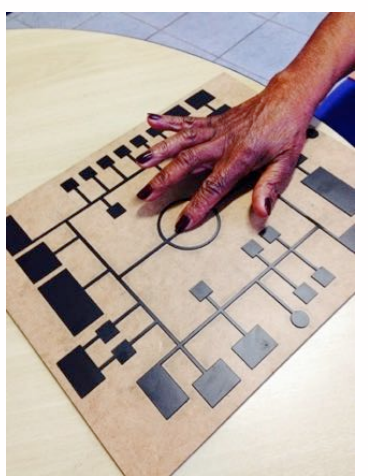

Fonte: o autor, 2015.
Figura 8. Realização do Percurso.

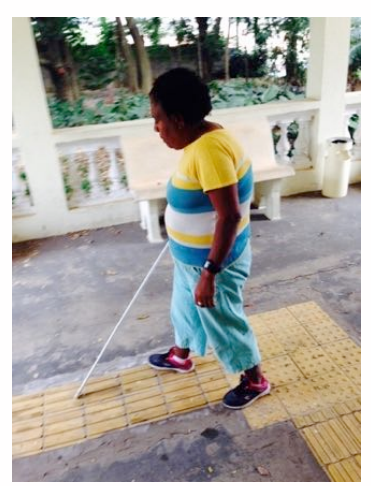

Fonte: o autor, 2015
Figura 9. Etapa de leitura manual da Maquete 01.

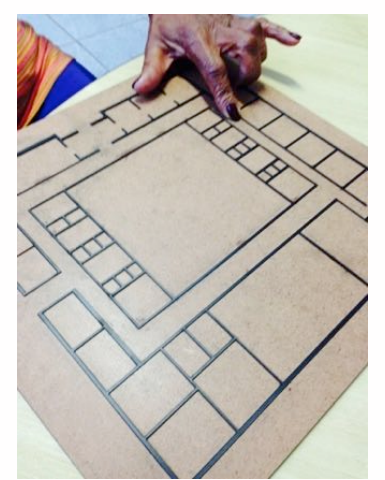

Fonte: o autor, 2015.

\subsubsection{Percurso}

O percurso 3 foi traçado com base no conhecimento geral mais comum entre os usuários do ICCT. De acordo com Carolina Roncasaglia, terapeuta ocupacional do Instituto, existem locais de maior conhecimento geral, e outros não tão detectados ou frequentado - como por exemplo, o "meio do jardim" e a "sala de telemarketing". Em meio a uma conversa, Roncasaglia ainda cita que os DVs sempre usam o mesmo caminho para chegar ao objetivo, e na maioria das vezes contam as portas e corrimãos para se orientar. A Figura 10 e Figura 11, descrevem o percurso explicado e aplicado em cada uma das maquetes 

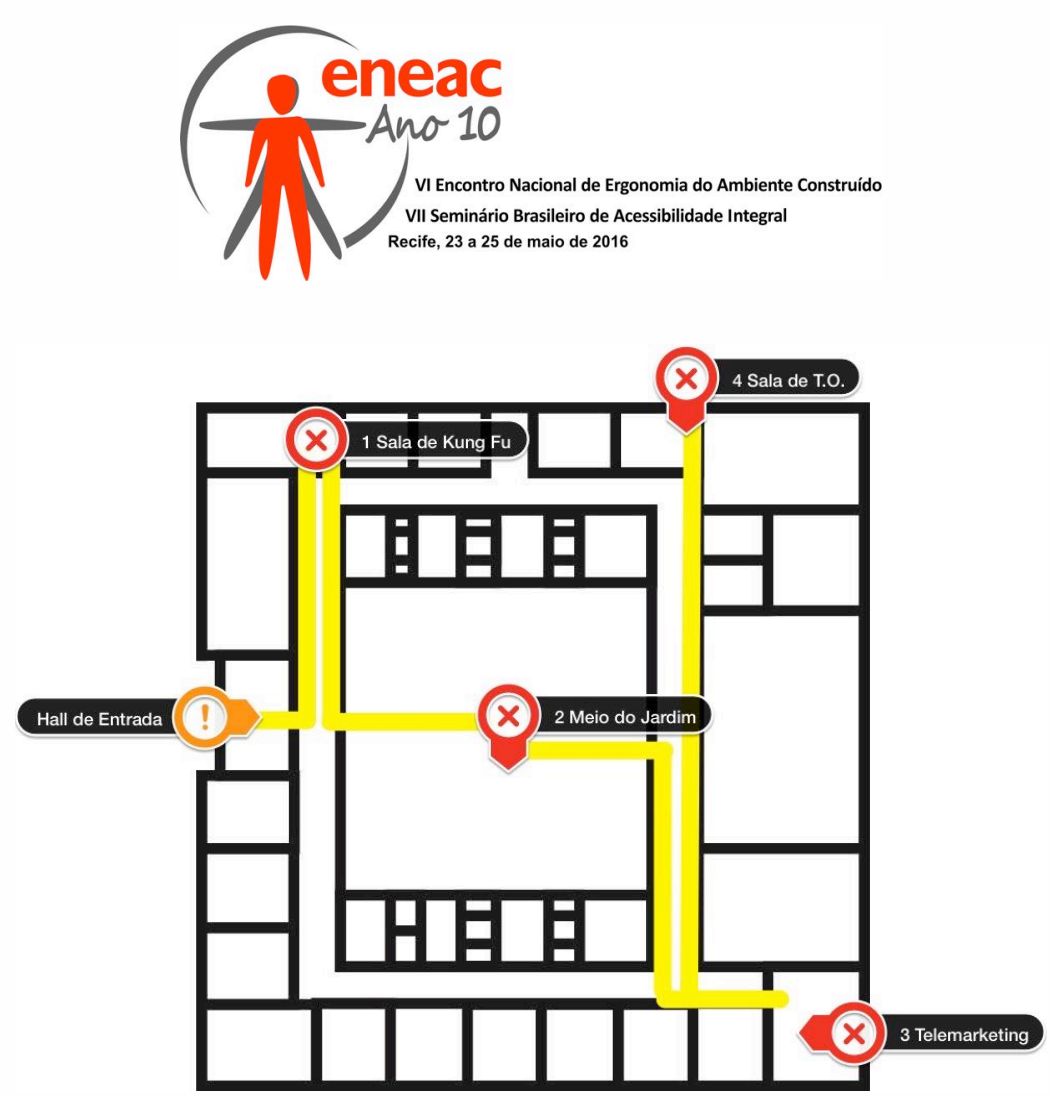

Fonte: o autor, 2015.

Figura 11 - Percurso da Maquete 02.

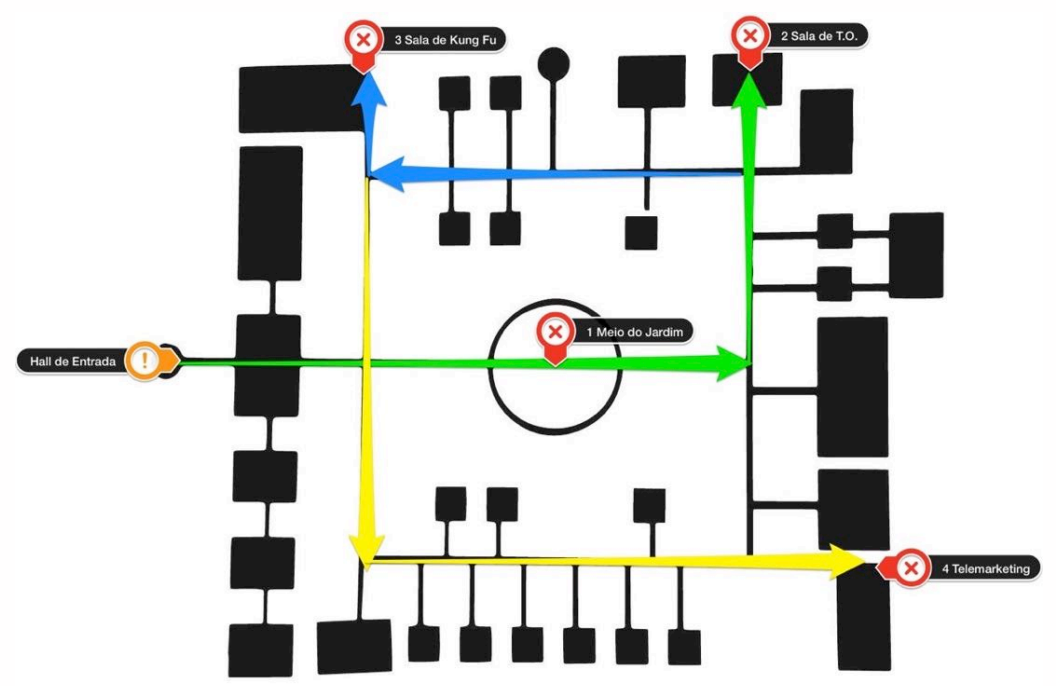

Fonte: o autor, 2015.

\section{RESULTADOS E DISCUSSÃO}

Analisando o questionário de cada voluntário nota-se pontos importantes que servem de finalização para este trabalho e continuação da pesquisa. Certos usuários e alunos membros da equipe técnica do ICCT, se agradaram de uma maquete tátil sem o uso do braille. Segundo relatos do local, poucos usuários do Instituto conhecem a linguagem. Verbalizar a localização dos ambientes facilitou a realização do experimento.

O tamanho da Maquete 02 recebeu aprovação total, pois obviamente independe de escala. Em compensação alguns relataram que a Maquete 01 poderia ser maior. Inicialmente, pensou-se em representar os vãos de todas as portas do edifício principal, como na Figura 12. Porém devido a escala construtiva dos artefatos fabricados esta ação poderia gerar uma 


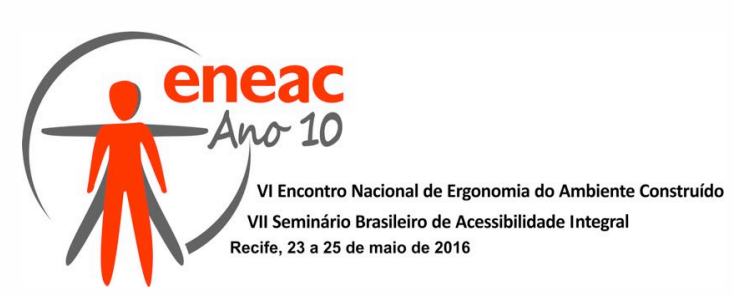

maquete com muitas pontas e informações, atrapalhando a leitura e discernimento do trajeto.

Figura 12 - Detalhe da maquete 01.

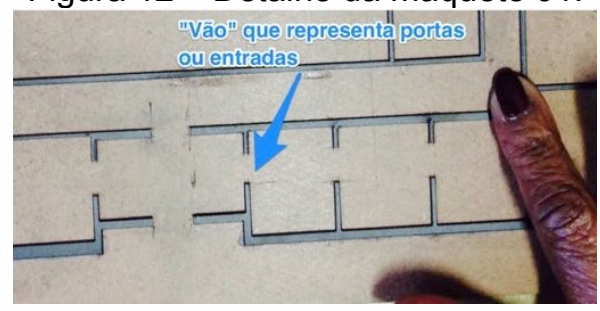

Fonte: o autor, 2015.

Tabela 1 - Síntese dos dados coletados na entrevista.

\begin{tabular}{|c|c|c|c|c|c|}
\hline ID & TIPO & $\begin{array}{c}\text { Caminhos ou } \\
\text { Espaços? }\end{array}$ & $\begin{array}{c}\text { Nivel de Segurança } \\
\text { com a maquete } \\
\text { escolhida. }\end{array}$ & Preferencia & $\begin{array}{c}\text { Gostaria de uma } \\
\text { maquete tátil que } \\
\text { pudesse levar pra casa? }\end{array}$ \\
\hline Voluntário 1 & Congênita & Caminhos & SEGURANÇA & Maquete 02 & SIM \\
\hline Voluntário 2 & Baixa Visão Adquirida & Espaços & INSEGURANÇA & Maquete 01 & SIM \\
\hline Voluntário 3 & Adquirida & Caminhos & SEGURANÇA & Maquete 01 & SIM \\
\hline Voluntário 4 & Congênita & Caminhos & SEGURANÇA & Maquete 02 & SIM \\
\hline Voluntário 5 & Baixa visão Congênita & Caminhos & INDIFERENTE & Maquete 02 & SIM \\
\hline
\end{tabular}

- Cegueira congênita compreendem melhor a linguagem da Maquete 02

- Cegueira adquirida compreendem melhor a linguagem da Maquete 01

- Cegueira congênita têm mais segurança para se locomover

- Todos preferem ter uma maquete fabricada digitalmente para levar pra casa, do que apenas uma no ICCT

Além de perguntas objetivas, foram feitas outras com o intuito de registrar, sob o ponto de vista de quem não vê, perguntas sobre o espaço e sobre arquitetura. Para os usuários com cegueira congênita (CC) o conceito de espaço parece um tanto quanto abstrato, assim como o conceito de arquitetura. Sendo esses tópicos, mais claros para os indivíduos entrevistados que possuíam baixa visão (BV), ou cegueira adquirida (CA).

Apesar disso, os CC são mais confiantes e exploradores do espaço ao redor, sendo melhores em desempenho de orientação espacial, e na leitura de linhas e formas geométrica para entendimento da volumetria do edifício; claramente se identificaram com a Maquete 02, de linguagem simples, pontual e mais abstrata.

Já os BV e os CA, tinham mais dificuldades para interpretar os mapas táteis, e de se orientar em novos trajetos, e acabaram se identificando mais com a Maquete 01, próxima da representação arquitetônica convencional. Constatou-se o cuidado e sensibilidade na elaboração desses mapas. O desenhista/projetista de objetos de orientação desse tipo deve estar atento ao fato de que mãos e olhos não enxergam o mundo da mesma forma, o que reforça a necessidade de utilização da percepção háptica/sinestésica na leitura de instrumentos de auxílio à locomoção.

\section{REFERÊNCIAS BIBLIOGRÁFICAS}




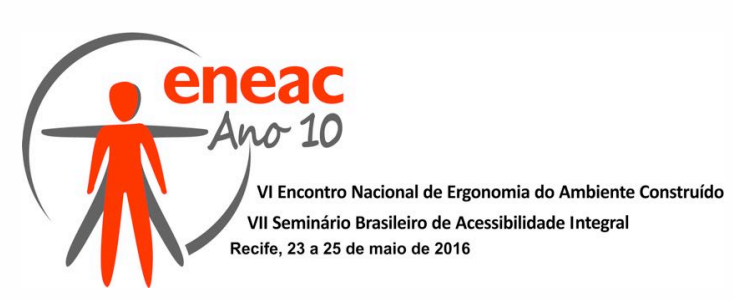

ALMEIDA, L. C.; LOCH, R. E. N.. Mapa tátil: passaporte para a inclusão. Extensio - revista eletrônica de extensão, n. 3, 2005.

AMIRALIAN, M. L. T. M. . Compreendendo o cego: uma visão psicanalítica da cegueira por meio de desenhos-estórias. São Paulo: Casa do Psicólogo. 1997

ARTHUR, P.; PASSINI, R. Wayfinding-People, Signs, and Architecture. (1a ed. 1992). McGrawHill, New York, 2002.

BALLASTERO, Jose Alfonso Alvarez. Multissensorialidade no ensino de desenhos a cegos. Dissertação de Mestrado. São Paulo: ECA-USP, 2003.

BELTRAMIN, Renata. Diretrizes para o projeto e execução de uma rota acessível e de um mapa tátil para o campus da unicamp. pg 1467. Anais do X Encontro Nacional e VI Encontro Latino Americano de Conforto no Ambiente Construído. 2009

BERGER, C. M. Wayfinding: designing and implementing graphic navigational systems. Inglaterra: Rotovi- sion, 2009.

CAPELI, G.A.; BERNARDI, N. ; d'ABREU, J. V.V. Construção de um Mapa Tátil Sonoro como Ferramenta de Inclusão: Auxílio na Orientação Espacial de Usuários com Deficiência Visual. Anais do III Encontro Nacional de Ergonomia do Construído e IV Seminário Brasileiro de Acessibilidade Integral, João Pessoa, 2011.

CARERI, Francesco. Walkscapes, o caminhar como prática estética. Editora G.Gili, Ltda. 2013.

HUNTER, Susan. Design Resources - DR-01 Architectural Wayfinding. DeA Center, University at Buffalo. 2010.

JOSÉ, Elizabete da Assunção \& COELHO, Maria Teresa. Problemas de aprendizagem. 8a edição. São Paulo: Ática, 1996.

LEFTERI, Chris. Así se hace: té cnicasle fabricació para diseñ de producto. Barcelona: Blume, 2008.

LYNCH, Kevin. A imagem da cidade. São Paulo: Martins Fontes, 1980.

NOGUEIRA, Ruth Emilia. Elaboração de mapas táteis em escala grande: $\mathrm{O}$ caso do mapa do campus da UFSC. III Simpó sißrasileiro de Cié nciaßeodé sicas Tecnologias da Geoinformac, ã o 2010.

OLIVEIRA, Ana Cláudia. Visualidade, entre significac, ã sensí ve inteligí velArtigo, congresso Educação e Realidade. 2005.

PALLASMA, Juhani. Os Olhos Da Pele. Editora Bookman, 2011.

POLLIO, V. Tratado de Arquitetura/ Vitrúvio. São Paulo: Martins Fontes, 2007.

POYARES, M.; GOLDFELD. POYARES, M.; GOLDFELD. Análise comparativa da brincadeira simbólica de crianças cegas congênitas e de visão normal. Revista Benjamin Constant, v. 40, 2008.

PUPO, Regiane. Implementando a fabricac, ã digital e a prototipagem rá pidæm cursos de arquitetura: dificuldades e realidades. Congresso SIGraDi, Havana, Cuba, 2008 